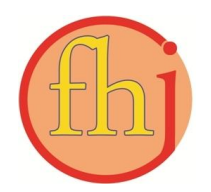

Faletehan Health Journal, 5 (3) (2018) 123-128

www. journal.Ippm-stikesfa.ac.id/ojs/index.php/FHJ

ISSN 2088-673X | e-ISSN 2597-8667

\title{
Pengaruh Senam Hamil Terhadap Kualitas Tidur Ibu Hamil Trimester II dan III di Kelurahan Margaluyu Wilayah Kerja Puskesmas Kasemen
}

\author{
Nila M arwiyah ${ }^{1}$, Fitria Sufi ${ }^{1}$ \\ ${ }^{1}$ Sekolah Tinggi Ilmu Kesehatan Faletehan, Serang, Indonesia \\ *Corresponding Author: nila_marwiyah@yahoo.com
}

\begin{abstract}
Abstrak
Kualitas tidur pada ibu hamil sangat penting untuk kesehatan ibu dan janin. Penyebab gangguan tidur ibu hamil karena bertambahnya berat janin, sesak nafas, pergerakan janin dan nyeri punggung. Untuk mengatasi hal tersebut diperlukan senam hamil yang meningkatkan kenyamanan pada ibu hamil.Penelitian ini bertujuan untuk mengetahui pengaruh senam hamil terhadap kualitas tidur ibu hamil. Penelitian ini merupakan penelitian Quasi Ekperiment Design dengan rancangan Pretest dan posttest without controldengan 14 respondenyang diambil menggunakan teknik total sampling. Pengumpulan data dilakukan dengan instrumenThe Pittsburgh Sleep Quality Index (PSQI) kemudian di analisis dengan mengunakan Uji T dependen. Hasil penelitian menunjukan bahwa nilai meankualitas tidur ibu hamil sebelum melakukan senam hamil adalah 12.43 dan nilai mean setelah pemberian senam hamil $6.43(p=0.000)$,dengan demikian ada pengaruh senam hamil terhadap kualitas tidur ibu hamil trimester II dan III. Maka dapat disimpulkan bahwa aktivitas senam hamil dapat menjadi salah satu upaya yang dapat dilakukan untuk meningkatkan kualitas tidur pada ibu hamil.

Kata Kunci: Ibu Hamil, Kualitas Tidur,PSQI, Senam Hamil
\end{abstract}

\begin{abstract}
Sleep quality in pregnant women is very important for the health of mother and fetus. In pregnant women, increased fetal weight, shortness of breath, fetal movements and back pain become the cause of sleep disorders. To overcome this, pregnancy exercise is needed which increases comfort for pregnant women. This study aims to determine the effect of pregnancy exercise on the quality of sleep for pregnant women. The research design was Quasi Experiment with pretest and posttest without control. The number of sampel were14 respondents taken by total sampling technique. Data collection was carried out with the Pittsburgh Sleep Quality Index (PSQI) instrument then analyzed using the dependent $T$ test. The results showed that the mean sleep quality of pregnant women before exercise was 12.43 and the mean after giving pregnant exercise was $6.43(p=0.000)$, thus there was the effect of pregnancy exercise on the sleep quality of second and third trimester pregnant women. So it can be concluded that pregnancy exercise can be an effort that can be done to improve the quality of sleep in pregnant women.
\end{abstract}

Keywords: Pregnancy Exercise, Pregnant Women, PSQI, Sleep Quality 


\section{Pendahuluan}

Gangguan pola tidur pada ibu hamil sering dirasakan saat kehamilan trimester II dan III, hal tersebut terjadi karena perubahan adaptasi fisiologis dan psikologis, perubahan fisiologis yang dialami ibu hamil, dikarenakan bertambahnya usia kehamilan seperti pembesaran perut, perubahan anatomis dan perubahan hormonal(Pilliteri, 2010). Selain itu ibu hamil juga suka mengalami nyeri punggung, susah bernafas, tidur, kurang nyenyak, sering kencing, kontraksi perut, pergelangan kaki membengkak, kram pada kaki (Hutchison, et al. 2012). Pertumbuhan janin yang sudah sedemikian membesar dapat menekan kandung kemih ibu, akibatnya kapasitas kandung kemih jadi terbatas sehingga ibu sering ingin buang air kecil, hal ini dapat menganggu istirahat ibu termasuk waktu tidurnya (Hutahaean, 2013). Ibu hamil yang mengalami gangguan pola tidur dapat mengganggu kesehatan fisik, seperti badan lemas dan daya tahan tubuh menurun sehingga mudah terserang penyakit.

Perubahan psikologis yang dialami ibu hamil lebih disebabkan karena kondisi cemas yang berlebihan, khawatir dan takut tanpa sebab, hingga akhirnya berujung pada kondisi depresi sehingga kualitas tidur pun terganggu. Kondisi stres inilah yang mengakibatkan otot tubuh menegang, terutama otot-otot yang berada di jalan lahir akan menjadi kaku dan keras sehingga mengganggu proses pembukaan jalan lahir. Selain itu ibu hamil yang mengalami gangguan tidur akan menjadilebih lamban menghadapi rangsangan dan sulit berkonsentrasi (Mirghaforvand, et al. 2017).

Dampak gangguan pola tidurjika terjadi secara berkepanjangan selama kehamilan maka dikhawatirkan bayi yang akan dilahirkan memiliki berat badan lahir rendah (BBLR), perkembangan sarafnya tidak seimbang, lahir prematur dan melemahnya sistem kekebalan tubuh bayi. Selain itu juga gangguan tidur menimbulkan depresi dan stres yang berpengaruh pada janin yang dikandungnya. Stres ringan menyebabkan janin mengalami peningkatan denyut jantung, tetapi stres yang berat dan lama akan membuat janin menjadi menjadi lebih hiperaktif (Okun, Schetter \& Glynn, 2011). Menurut Wangel, et al.(2011) gangguan pola tidur pada ibu hamil juga dapat meningkatkan persalinan lama yang berujung pada persalinan secara operasi sesar.
Menurut Bustami, dkk. (2016) mengatakan bahwa terdapat hubungan antara kualitas tidur dengan preeklamsia dimana uji analisis Chi-Square didapatkan nilai $\mathrm{p}$ sebesar 0,001 sehingga $\mathrm{Ha}$ diterima ( $\mathrm{p}<0,05)$. Hal ini di karenakan pada saat stressor datang disebabkan oleh gangguan tidur, maka hormone norepinefrin dan epinefrin disekresikan oleh kelenjar medulla adrenal dan efek dari perangsangannya yaitu langsung pada organ-organ spesifik seperti pembuluh darah dan jantung. Kedua hormon tersebut langsung membuat pembuluh darah setiap jaringan akan mengalami vasokontriksi sehingga membuat tahanan perifer meningkat yang akhirnya dapat meningkatkan tekanan darah (Delaune \& Ladner, 2011).

National Sleep Foundation (2007) menyatakan bahwa $97,3 \%$ wanita hamil trimester ketiga selalu terbangun dimalam hari dan rata rata sekitar $78 \%$ wanita hamil di Amerika mengalami gangguan tidur. Menurut Reichner (2015) mengatakan bahwa gangguan pola tidur pada trimester pertama sebanyak $13 \%$, trimester kedua $19 \%$ dan meningkat di trimester akhir yaitu sebesar 66\%. Fernandez-Alfonson, TrabalonPastor (2012) mengatakan bahwa dari 73,5\% ibu hamil yang mengalami insomnia terjadi pada kehamilan 39 minggu, dimana insomnia ringan sebanyak $50,5 \%$, insomnia sedang $15,7 \%$ dan insomnia berat sebanyak 3,8\%.

Tidur yang cukup akan membuat ibu hamil lebih bugar dan sehat sehingga dapat beraktifitas dengan baik, janin yang dikandungnya pun akan tumbuh dengan sehat. Oleh karena itu, ibu hamil harus mengupayakan agar kecukupan tidurnya terpenuhi, yakni sekitar 7-8 jam perhari.Kebutuhan ini bisa terpenuhi dari tidur malam atau di kombinasikan dengan tidur siang.Jika tidur malam hanya bisa dilakukan 5-6 jam maka tidur siang perlu dilakukan 1-2 jam sehingga kebutuhan tidur tercukupi. Lebih baik lagi bila ibu hamil tidur hingga 9 jam perhari (Indivara, 2009).

Upaya-upaya yang dapat dilakukan untuk mengatasi kesulitan tidur pada ibu hamil antara lain antara lain dengan melakukan olahraga ringan yang aman untuk ibu hamil, hipnoterapi, memberikan pendidikan kesehatan bagaimana menjaga kualitas tidur dan latihan relaksasi (Hegard, 2010). Olah raga di pagi hari seperti jalan-jalan pagi hari atau olahraga yang bersifat kelompok seperti senam hamil bisa dilakukan 
Faletehan Health Journal, 5 (3) (2018) 123-128

www. journal.Ippm-stikesfa.ac.id/ojs/index.php/FHJ

ISSN 2088-673X| 2597-8667

untuk memperlancar sirkulasi darah ibu dan meningkatkan relaksasi pada ibu hamil bisa dilakukan secera rutin (Roosytasari, 2009). Wanita hamil dianjurkan melakukan olahraga ringan seperti senam hamil agar ibu dan janin lebih sehat dan berkurangnya masalah-masalah yang timbul pada kehamilannnya. Dalam gerakan senam hamil terkandung efek relaksasi yang bermanfaat menstabilkan kecemasan dan mengurangi rasa takut dengan cara relaksasi fisik dan mental, serta mendapatkan informasi yang mempersiapkan mereka untuk mengalami apa yang akan terjadi selama persalinan dan kelahiran (Brayshaw, 2008).

Untuk menangani masalah ganggun tidur pada ibu hamil, kita dapat memberikan beberapa metode untuk menstabilkan kualitas tidur yang baik, seperti menentukan posisi yang baik dan nyaman saat tidur, latihan relaksasi dasar, salah satunya dengan senam hamil. Senam hamil dapat berdampak positif untuk mengatasi gangguan tidur, namun penerapan senam hamil ini masih jarang digunakan, karena kurangnya kesadaran ibu hamil akan pentingnya senam hamil (Brayshaw, 2008).

Penelitian Wahyuni dan Ni'mah (2012) menunjukkan bahwa senam hamil berpengaruh dalam peningkatan durasi tidur ibu hamil pada trimester III.Terdapat 9 ibu hamil trimester III yang melakukan senam hamil selama 4 minggu, dengan pertemuan $2 \mathrm{x}$ dalam satu minggu.Waktu senam hamil adalah $\leq 30$ menit.Penelitian ini juga menyatakan bahwa senam hamil akan memberikan efek relaksasi pada ibu hamil yang bisa berpengaruh terhadap peningkatan durasi tidur bagi ibu hamil.

Penelitian Aliyah (2016) menunjukkan bahwa senam hamil berpengaruh dalam meningkatkan durasi tidur ibu hamil trimester III. Penelitian dilakukan pada 22 da ibu hamil trimester II dan III dengan jumlah pertemuan adalah 6 kali pertemuan, 2 kali dalam seminggu. Penelitian ini juga menyatakan bahwa senam hamil memberikan efek relaksasi pada ibu hamil yang bisa berpengaruh terhadap durasi tidur bagi ibu hamil.

Berdasarkan hasil wawancara pada ibu hamil yang berada di Kelurahan Margaluyu berjumlah 13 Ibu Hamil Trimester I-III, 11 Ibu hamil mengatakan sering merasakan gangguan dalam tidur, hal ini dikarenakan meningkatknya frekuensi buang air kecil selain itu juga sering mengalami kecemasan, rasa takut, khawatir akan kehaamilan dan proses persalinan, dan ibu hamil juga tidak mengetahui bahwa senam hamil dapat membantu ibu hamil dalam memperbaiki kualitas tidur yang buruk menjadi kualitas tidur yang baik.

Mengingat pentingnya manfaat senam hamil sebagai salah satu alternatif untuk mengurangi keluhan-keluhan ibu hamil yang mengakibatkan penurunan durasi waktu tidur, maka peneliti tertarik untuk melakukan penelitian tentang Pengaruh senam hamil terhadap kualitas tidur ibu hamil trimester II dan III di Kelurahan Margaluyu Tahun 2017.

\section{Metode Penelitian}

Penelitian ini menggunakan desain quasi experiment pre post without control.Hal pertama yang dilakukan pada penelitian ini adalah memberikan pretest (Q1) pada subjek untuk mengetahui kualitas tidur sebelum perlakuan. Selanjutnya diberikan treatment $(\mathrm{X})$ berupa senam hamil pada subjek sebanyak 6 kali pertemuan dalam 3 minggu.Kemudian dilakukan posttest (Q2) pada subjek untuk kualitas tidur setelah perlakuan.Hasil dari Q1 dan Q2 lalu dibandingkan untuk melihat perbandingan pre-test dan post-test pada subjek. Adapun jumlah sampel pada penelitian ini adalah berjumlah 14 orang ibu hamil. Pengumpulan data menggunakan instrument Pittsburgh Sleep Quality Indeks (PSQI) dan di analisis dengan menggunakan uji $\mathrm{T}$ dependen.

Instrumen kualitas tidur dengan menggunakan Pittsburgh Sleep Quality Indeks (PSQI) dimana instrumen ini sudah di alih bahasakan dan di uji validitas dan reabilitas oleh Dewantri (2016) yang dilakukan pada 30 responden dengan nilai $r$ tabel 0,361. Uji validitas instrumen kualitas tidur didapatkan nilai korelasi validitas berkisar 0,474 0,607 dan nilai Cronbach's Alpha 0,830, sehingga instrumen di katakan valid dan reliabel untuk di jadikan instrumen.

\section{Hasil dan Pembahasan}

Hasil penelitian menunjukan bahwa rata-rata kualitas tidur ibu hamil di Kelurahan Margaluyu Wilayah Keja Puskesmas Kasemen sebelum diberikan senam hamil adalah 12.43 dan sesudah dilakukan senam hamil sebanyak 6 kali selama 3 minggu mengalami penurunan sebesar 6,43 . Hasil uji statistik dengan menggunakan uji t dependen didapatkan $p$ value 0,000 berarti $p<\alpha$ (0.05).dengan demikian maka Ho ditolak, sehingga dapat dinyatakan terdapat perbedaan antara rerata 
kualitas tidur sebelum dengan sesudah intervensi senam hamil. Hal ini membuktikan bahwa ada pengaruh yang signifikan antara pemberian senam hamil terhadap kualitastidur ibu hamil.

Kualitas tidur adalah suatu ukuran dimana seseorang mendapatkan kemudahan untuk memulai tidur, mampu mempertahankan kualitas tidur dan merasa rileks setelah terbangun dari tidur.Kualitas tidur mempengaruhi kesehatan dan kualitas hidup secara keseluruhan (Delaune \& Ladner, 2011). Kualitas ibu saat kehamilan banyak di pengaruhi perubahan fisik dan psikologis yang dialaminya.

Secara fisiologis keluhan tidur yang dialami ibu hamil disebabkan oleh pertumbuhan janin dan pergerakan janin yang dapat menekan kandung kemih sehingga dapat meningkatkan frekuensi buang air kecil, beban tubuh yang semakin berat sehingga dapat merubah struktur tulang belakang sehingga ibu hamil dapat merasakan ketidaknyamanan di daerah pinggang, begitu juga di bagian ektremitas yang terkadang ibu hamil suka mengalami kram. Kondisi ini juga dapat menimbulkan perubahan psikologis ibu hamil, yang terkadang perubahan fisik yang dialaminya dapat menimbulkan kecemasan, dan kekhawatiran saat menghadapi persalinan, hal ini yang terkadang dapat mempengaruhi kualitas tidur ibu hamil (Pilliteri, 2010).

Kualitas tidur ibu hamil di Kelurahan Margaluyu Wilayah Kerja Puskesmas Kesemen sebelum dilakukan intervensi dalam tahap kualitas tidur yang buruk, dimana rata-rata sebelum di lakukan intervensi 12,43, hal ini di karenakan ibu hamil di Desa Margaluyu ibu sering terbangun ditengah malam untuk ke kamar mandi, terasa nyeri saat tidur, tidak mampu bernapas dengan leluasa, cemas terhadap kondisi janin dan juga proses persalinan, karena tidur malam terganggu pada malam hari sehingga pada siang hari ibu hamil sering mengantuk hal ini juga di sampaikan oleh ibu hamil bahwa mereka tidak pernah melakukan senam hamil dan hanya melakukan jalan santai di pagi hari.

Gangguan kulaitas tidur pada ibu hamil dapat berdampak pada kondisi ibu hamil dan janin. Ibu hamil yang mengalami gangguan pola tidur dapat menurunkan kekebalan tubuh yang memudahkan ibu untuk terkena penyakit, dan juga menyebabkan tubuh menjadi mudah lelah, badan terasa pegal dan mudah emosional, jika hal ini berkelanjutan kan menimbulkan stress dan depresi. Kondisi ini akan mengganggu sirkulasi darah ke janin sehingga memperbesar resiko berat badan bayi lahir rendah dan mengalami komplikasi penyakit pada janin (Okun, Schetter \& Glynn, 2011).

Upaya yang dilakukan untuk mengatasi masalah pola tidur pada ibu hamil salah satunya adalah dengan melakukan latihan gerak tubuh, relaksasi, dan mengatur pola nafas ibu yang di sebabkan pembesaran uterus yang mendesak dinding diafragma. Latihan gerak bisa dilakukan dengan menggunakan metoda senam hamil. Senam Hamil dapat bermanfaat untuk meningkatkan sirkulasi oksigen ke otot dan jaringan tubuh, serta memperlancar peredaran darah, adapun tujuan senam hamil untuk pembentukan sikap tubuh, merengangkan dan menguatkan otot terutama otot yang berperan dalam persalinan serta memperbaiki kerja jantung, pembuluh darah, dan paru dalam mengedarkan nutrisi dan oksigen keseluruh tubuh. Sehingga dapat menurunkan ketidaknyamanan fisik dan mengurangi keluhan-keluhan ibu hamil (Kemenkes RI, 2010).

Untuk mengatasi gangguan tidur yang buruk pada ibu hamil di Desa Margaluyu maka pada wanita hamil trimester II dan III dilatih untuk melakukan senam hamil sebanyak 6 kali yang dilakukan 1 minggu 2 kali. Selain memberikan intervensi senam hamil, responden pun diberikan buku panduan senam hamil yang bertujuan untuk meningkatkan kembali informasi yang telah disampaikan oleh peneliti.Sehingga ini berguna untuk meningkatkan pengetahuan ibu hamil terhadap senam hamil.

Tabel Rerata dan perbedaan Kualitas Tidur Ibu Hamil Trimester II Dan III Sebelum dan Sesudah Intervensi di Kelurahan Margaluyu Wilayah Kerja Puskesmas Kasemen Tahun 2017 (n=14)

\begin{tabular}{lccccc}
\hline \multicolumn{1}{c}{ Variabel } & Mean & SD & Minimal - maksimal & $95 \%$ CI & \multirow{2}{*}{ Value } \\
\hline Total Pretest & 12.43 & 1.555 & $10-15$ & $11.53-13.33$ & \multirow{2}{*}{0} \\
\hline Total Posttest & 6.43 & 1.651 & $4-9$ & $5.43-7.38$ & \\
\hline
\end{tabular}


Faletehan Health Journal, 5 (3) (2018) 123-128

www. journal..lppm-stikesfa.ac.id/ojs/index.php/FHJ

ISSN 2088-673X| 2597-8667

Hasil analisis peneliti tentang pengaruh senam hamil terhadap kualitas tidur ibu hamil sama halnya dengan penelitian yang dilakukan oleh Aliyah (2016) terdapat 22 responden ibu hamil trimester II dan III yang dilakukan 1 minggu 2 kali, dalam 3 minggu, menunjukkan bahwa setelah melakukan senam hamil kualitas tidur ibu hamil yaitu sebanyak 16 responden (59.3\%) menunjukkan kualitas tidur baik dan 6 responden (22.2\%) menunjukkan kualitas tidur buruk.Nilai signifikansi pada data posttest kualitas tidur sebesar 0.038 .

Hasil analisis penelitian bahwa dengan pemberian senam hamil dapat memberikan pengaruh yang positif terutama terhadap kualitas tidur ibu selama kehamilan. Hal ini di karenakan senam hamil merupakan suatu latihan pada ibu hamil yang bertujuan untuk membantu otot dinding perut menjadi elastis pada saat pembearan uterus, memperbaiki keseimbangan fisik ibu hamil, membantu meningkatkan posisi ibu yang benar selam kehamilan dan juga melancarkan peredaran darah ibu sehingga meningkatkan kenyamanan ibu pada saat masa kehamilan (Kemenkes, RI, 2010). Hal ini sesuai dengaan penelitian yang dilakukan oleh Wagey (2011) tentang senam hamil yang menyebutkan bahwa $63,8 \%$ responden yang mendapatkan senam hamil memiliki kekuatan otot panggul dan kualitas jasmani semakin meningkat.

Penelitian yang dilakukan oleh Purba (2018) mengatakan bahwa senam hamil yang dilakukan selama 8 kali memiliki pengaruh yang signifikan dengan nilai $p(0,000)$ antara kelompok kontrol dan kelompok intervensi, dimana kelompok intervensi setelah di berikan senam hamil memiliki rata-rata kualitas tidur sebesar 7,80 sedangkan kelompok intervensi rata-rata kualitas tidur sebesar 10,70.

Kurang tidur yang berkepanjangan dapat mengganggu kesehatan fisik dan psikis. Kurang tidur dari segi fisik, akan menyebabkan muka pucat, badan lemas dan daya tahan tubuh menurun sehingga mudah terserang penyakit. Kurang tidur dari segi psikis, akan menyebabkan timbulnya perubahan suasana kejiwaan, sehingga penderita akan menjadi lesu, lamban menghadapi rangsangan dan sulit berkonsentrasi. Menurut Indivara (2009) Tidur yang cukup akan membuat ibu hamil lebih bugar dan sehat sehingga dapat beraktifitas dengan baik, janin yang dikandungnya pun akan tumbuh dengan sehat. Oleh karena itu, ibu hamil harus mengupayakan agar kecukupan tidurnya terpenuhi, yakni sekitar 7-8 jam perhari. Lebih baik lagi bila ibu hamil tidur hingga 9 jam perhari.

Menurut Fauziah \& Sutejo (2012) ibu yang tidak melakukan senam hamil dapat menyebabkan kualitas tidur tidak terpenuhi, sehingga timbulnya rasa tidak nyaman, bangun tidur di pagi hari dengan suasana yang tidak menyenangkan dan bila ini terjadi secara berkepanjangn selama kehamilan maka dikhawatirkan bayi akan dilahirkan dengan berat badan lahir rendah (BBLR), perkembangan sarafnya tidak seimbang dan melemahnya sistem kekebalan tubuh bayi. Oleh karena itu metode senam hamil harus dilakukan secara rutin.

Senam hamil merupakan salah satu pelayanan prenatal care yang dapat meningkatkan kenyamanan pada ibu hamil dan menurunkan kecemaasan pada ibu hamil, dengan melakukan senam hamil maka dapat memperlancar sirkulasi peredaran darah ketubuh dan janin, selain itu memperkuat dan membuat elastisitat otot-oto panggul, menjaga persendian, melatih otot-otot pernafasan dan juga meningkatkan kenyamanan pada ibu hamil (Brayshaw, 2008).

\section{Simpulan}

Kualitas tidur ibu hamil dapat di pengaruhi perubahan anatomi dan fisiologi tubuh ibu hamil dan perkembangan janin, sehingga menimbulkan dampak ketidaknyamanan saat tidur, sesak nafas, sering buang air kecil dan kram di daeraah kaki, di dukung lagi dengan rasa cemas yang dialami oleh ibu hamil terhadap perkembangan jaanin dan proses persalinan yang akan dialaluinyaa, hal ini akan menimbulkan gangguan pola tidur ibu sehingga mencapai kualitas tidur yang buruk. Untuk mengatasi hal tersebut diperlukannya aktifitas fisik seperti senam hamil, hal ini bertujuan untuk meningkatkan sirkulasi darah dan nutrisi keseluruh tubuh, membuat relaksasi otot panggul dan otot-otot rahim.

Kondisi ibu hamil di Kelurahan Margaluyu mengalami kualitas tidur yang buruk sebesar 12,43 dan setelah dilakukan intervensi yaitu di latih senam hamil sebanyak 6 kali selama 3 minggu, maka ada perubahan pada kualitas tidur menjadi 6,43. Hal ini dapat dijadikan masukan bagi Puskesmas Kesemen untuk meningkatkan program kelas senam hamil di Desa Margaluyu dan meningkatkan motivasi ibu hamil untuk menjaga kualitas tidur yang bertujuan untuk meningkatkan kesehatan ibu dan janin selama kehamilan. 


\section{Referensi}

Aliyah, J. (2016). Pengaruh Pemberian Senam Hamil Terhadap Tingkat Kecemasan Dan Kualitas Tidur Ibu Hamil Di Puskesmas Samata Kabupaten Gowa Makassar :Skripsi.Program Studi Fisioterapi Fakultas Kedokteran Universitas Hasanuddin. repository.unhas.ac.id/handle/123456789/19340

Bustami, dkk. (2016). Hubungan kualitas tidur dengan kejadian preeklamsia pada ibu hamil.Jornal of Midwafery.Vol 1, No 1https://doi.org/10.25077/jom.1.1.35-44.2016

Brayshaw, E. (2008). Senam Hamil Dan Senam Nifas. Jakarta : EGC.

Delaune, S.C., \&Lander, P.K. (2011). Fudamentals of Nursing: Standars and practice, Fourth Edition. Cengage Learning. Delmar. https://pdfs.semanticscholar.org

Dewantri.A. (2015).Gambaran Kualitas Tidur Pada Mahasiswa Profesi Ners Program Studi Ilmu Keperawatan Universitas Diponegoro dan Stikes Ngudi Waluyo Semarang. http://eprints.undip.ac.id.

Fauziah, S., \& Sutejo. (2012). Buku Ajar Keperawatan Maternitas Kehamilan. Jakarta:Kencana Prenada Group.

Fernandez-Alfonson, A.M. \& Trabalon-Pastor, M. (2012). Factors related to insomnia and sleepiness in the late third trimester of pregnancy. Arch Gynecol Obstet ; 286: 5561.https://link.springer.com.

Hegard, H, K. (2010). Experience of Physical Activity During Pregnancy in Danish Nulliparous Women With A Physically Active Life Before Pregnan cy, A Qualitative Study. BMC Pregnancy and Childbirth, 10(33). https://bmcpregnancychildbirth.biomedcentral .com/articles/10.1186/1471-2393-10-33

Hutahaean, S. (2013).Perawatan Antenatal. Jakarta : Salemba Medika.

Hutchison B.L., Stone P.R., Mccowan L.M., Stewart A.W., Thompson J.M., Mitchell E.A. (2012). A postal survey of maternal sleep in late pregnancy. BMC Pregnancy Childbirth.2012;12:144 doi: 10.1186/14712393-12-144.

Indivara. (2009). The Mom's Secret. Yogyakarta: Pustaka Anggrek.

Kemenkes RI, (2010). Panduan tehnis latihan fisik selama kehamilan dan nifas. http://dosen.stikesdhb.ac.id
Mirghaforvand, M; Mohammad-AlizadehCharandabi, S; Zarei, S; Effati- Daryanii, F; Sarand, F. Z. (2017). The relationship between depression and sleep quality among pregnant women in Tabriz-Iran. International Journal of Women's Health and Reproduction Sciences.https://www.researchgate.net

National Sleep Foundation.(2007). Sleepingthetrimester-3 $3^{\text {rd }}$-trimester. https://www.sleepfoundation.org

Okun, M.L., Schetter, C.D., \&Glynn, L.M. (2011). Poor sleep quality is associated with preterm birth. Sleep; 34:1493e8. https://academic. oup.com.

Pilliteri, A. (2010). Maternal \& child health nursing: Care of the childbearing and childrearing famili $\left(6^{\text {th }} e d\right)$. Philadelpia: Lippincott Williams \& Wilkins.

Purba, R.A. (2018). Pengaruh senam hamil terhadap kualitas tidur ibu hamil trimester III di Mommies Clinic Surakarta. Skripsi. Universitas Muhammadiyah Suraakarta.

Reichner, C.A. (2015) . Insomnia and sleep deficiency in pregnancy. Obstetric Medicine, Vol. 8(4) 168-171. DOI: 10.1177/ $1753495 X 15600572$

Roosytasari, L. (2009). Hubungan Antara Senam Hamil DenganProses Pers alinan Normal DiRumah Bersalin As Syifa'ul Ummah Grobogan. Skripsi thesis, Universitas Muhammadiyah Surakarta. http://eprints.ums.ac.id

Utami, AP. P. (2015). Hubungan frekwensi senam hamil dengan kualitas tidur pada ibu hamil. Sripsi. STIKES NU Tuban. http://lppm. stikesnu.com.

Wagey, F.W. (2011).Senam Hamil Meningkatkan Antioksidan Enzimatik, Kekuatan Otot Panggul, Kualitas Jasmani dan Menurunkan Kerusakan Oksidatif pada Wanita Hamil. Denpasar:Universitas Udayana.

Wahyuni, dan Layinatun, N. (2012).Manfaat Senam Hamil Untuk Meningkatkan Durasi Tidur Ibu Hamil. http://journal.unnes.ac.id.

Wangel, A.M., et al. (2011). Emergency cesarean sections can be predicted by markers of stress, worry and sleep disturbances in first-time mothers. Acta Obstet Gynecol Scand ; 90: 238244. https://obgyn.onlinelibrary.wiley.com.

Widianti, N. (2009). Efektivitas Senam Hamil Untuk Mengurangi Kecemasan Pada Ibu Hamil. Semarang: Universitas Katolik Soegijapranata. http://repository.unika.ac.id. 